Brit. J. industr. Med., 1951, 8, 218.

\title{
THE EFFECTS OF BAL ON THE METABOLISM OF LEAD AND ON THE SYMPTOMATOLOGY IN LEAD INTOXICATION*
}

\author{
BY
}

\author{
E. C. VIGLIANI and N. ZURLO
}

From the Clinica del Lavoro Luigi Devoto and from the Research Laboratory of the I.N.A.I.L., Milan

The effects of injection of BAL on the metabolism of lead has been studied by Eagle (1948) and by Ginsburg and Weatherall (1948) in animals poisoned with lead acetate, and by Ryder, Cholak, and Kehoe (1947) in human cases of acute lead poisoning.

The action of BAL has been shown to be the same both in experimental animals and in man; in animals it had no demonstrably protective action, and on occasion appeared to accelerate the toxic effects of lead acetate in rabbits ; similarly in man, three days' treatment with $1.7 \mathrm{~g}$. of BAL was without beneficial effect. Characteristic effects were observed on the metabolism of lead, inasmuch as there followed a rapid drop in the lead concentration in the red blood cells, and an immediate rise in urinary lead concentration, to a degree far greater than that observed from any other kind of treatment. The plasma and faecal lead concentration were unchanged by BAL treatment.

Eagle (1948) advised caution in the use of BAL, although he did not see evidence in man of toxic effects in cases of lead poisoning. He recommended four-hourly injections of $2.5 \mathrm{mg}$. per $\mathrm{kg}$. body weight repeated four times a day and continued for two to four days, diminishing thereafter gradually to about two injections a day.

Ginsburg and Weatherall (1948) used the Th. $\beta$ isotope of lead to study lead acetate distribution in tissues. Administration of lead acetate was followed by $50 \mathrm{mg}$. per $\mathrm{kg}$. BAL up to 23 hours later. This resulted in increased urinary excretion of lead and a shift in the tissue distribution from the liver, the spleen, the red cells, and the bone marrow to the skeletal and cardiac muscle.

Our studies on BAL treatment in human cases of lead intoxication were started two years before read-

\footnotetext{
* Rendered into English by Dr. M. W. Goldblatt.
}

ing Eagle's report. The first results of our studies were referred to by Angeleri (1949) and later at the International Meeting on Industrial Medicine held in Milan in June, 1950 (Vigliani, Zurlo, Angeleri, Meschia, and Sartorelli, 1951). In this communication we shall report on those early results and also on more recent results obtained since June, 1950.

\section{Results}

Twenty-seven patients ( 25 men and two women) with occupational lead poisoning have been treated with BAL ; fourteen of these were suffering from acute lead colic on their admission to hospital, and the others had had lead colic some few days or weeks before. The doses of BAL used were generally low ; in no case was more than $450 \mathrm{mg}$. injected on any day ; in a few cases the dose was 50 to 100 mg. a day. Such low doses were held to be necessary on account of the adverse disturbances to which BAL gives rise in lead colic, and to which we shall refer later. In 14 of the patients blood and urine lead were studied using the dithizone method; in three cases the method was applied to the bile and the gastric juice.

In most cases the excretion of urinary coproporphyrin was studied both immediately before and at periods after the injection of BAL, either from day to day for a few days or, in some cases, for weeks.

Lead in Blood.-The average value of lead in the blood of our patients taken in the morning before breakfast and before any treatment with BAL was $122 \mu \mathrm{g} . \%$. (In the cases with active colic the average value was $138 \mu \mathrm{g} . \%$ and in that of the remainder $116 \mu \mathrm{g} . \%$.)

Injection of 2 to $5 \mathrm{mg}$. per $\mathrm{kg}$. BAL brought about a marked reduction of the lead in the blood, this effect being reached a few minutes after the injection and attaining its greatest intensity some 


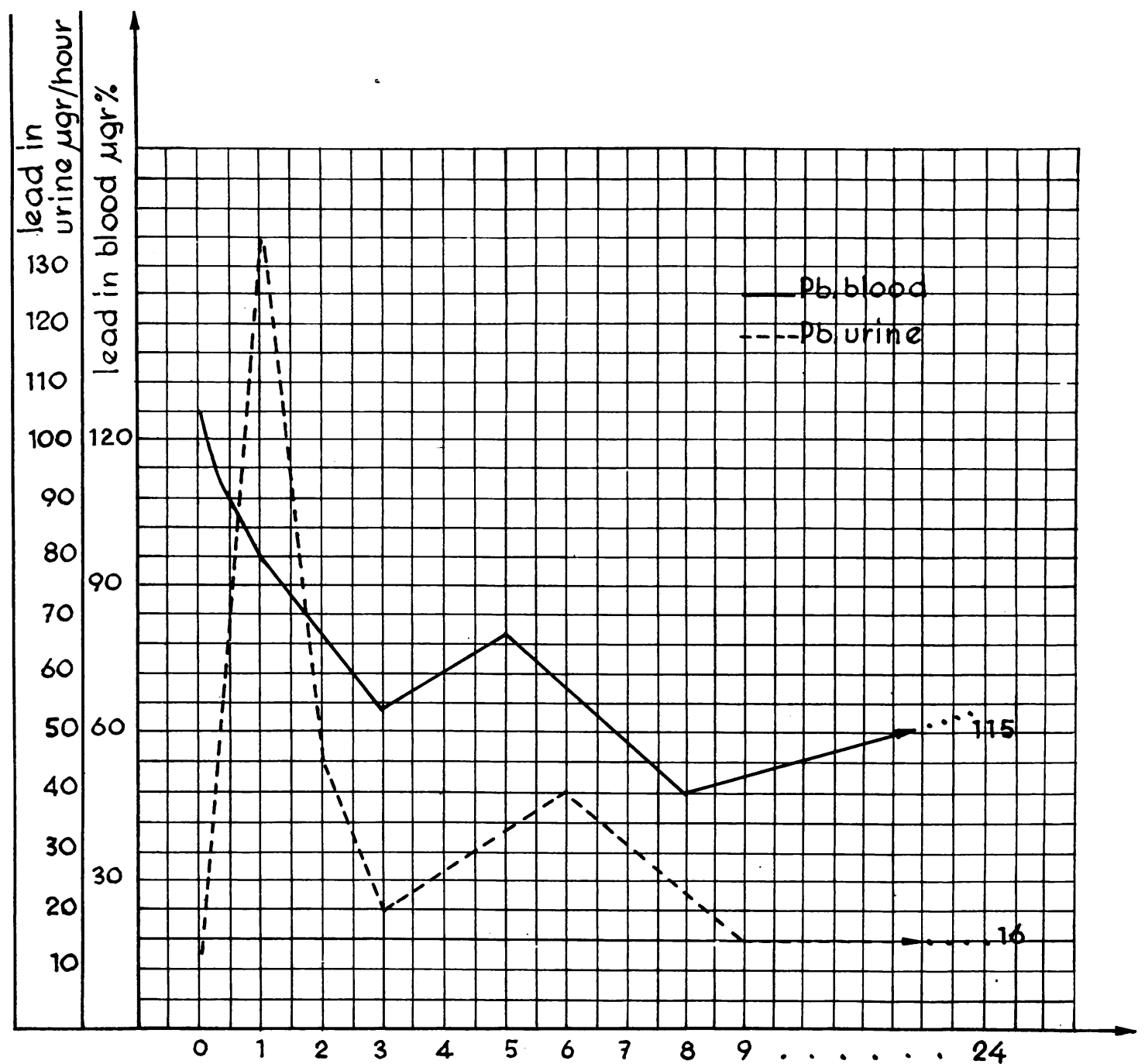

Fig. 1.-Behaviour of lead in blood and urine following an injection of 2-5 mg./kg. BAL (mean of 10 cases).

eight to 10 hours later. This fall was very often interrupted between the third and the eighth hour by a sudden increase, sometimes slight, sometimes quite considerable. Twenty-four hours after the injection, the lead in the blood had risen to 80 to $90 \%$ of its level before the injection (Fig. 1). One patient received $50 \mathrm{mg}$. BAL on one day, and $150 \mathrm{mg}$. two days later; the degree of reduction of the blood lead level was the same on both occasions.

A series of one to three injections per day of BAL for several days in doses varying from 2 to 7 $\mathrm{mg}$. per $\mathrm{kg}$. daily caused a progressive reduction in the lead content of the blood, sometimes sufficient to reduce it to $30 \%$ of the value before treatment. Cessation of treatment with BAL was followed by a rise until the lead content returned in a few days to the level before treatment (Fig. 2).

In two cases the lead content was determined separately in the clot and in the serum before and two hours after injection of BAL. No change in the serum lead was detected.

Lead in Urine.-In our cases the average excretion of lead in the urine before treatment with BAL was $12.6 \mu \mathrm{g}$. per hour ; in the cases of active colic it 
was $14.6 \mu \mathrm{g}$. per hour and in the remainder $11 \cdot 2 \mu \mathrm{g}$. per hour.

A single injection of BAL, even a dose of $50 \mathrm{mg}$., caused the lead to increase markedly in the first hour, reaching a level six to 25 times (average 13.3 times) greater than the average hourly excretion before the injection. In the second hour the lead excretion was still two to nine times (average four) greater than the pre-injection level. The level then rapidly diminished, although it remained higher than the pre-injection value throughout the day. In the 24 hours following treatment with BAL the lead eliminated in the urine was on the average 2.6 times higher than in the 24 hours prior to it (Fig. 1). The major portion of the lead excreted in the 24 hours following the injection of BAL was eliminated in the first three hours.

It will be seen that the amount of lead excreted in the urine is not proportional to the level of lead in the blood ; there is considerable variation in the capacity of different subjects to excrete lead in the urine. It follows, therefore, that the ratio between the 24 hour urinary lead and the blood lead concentration is not constant from one individual to another.

In our cases the increase in lead excretion brought about by BAL was not so much related to the quantity of BAL injected as to the pre-injection ratio between the 24-hour urinary lead excreted and the concentration of lead in the blood : the higher this ratio was, the greater was the increase in the excretion of lead brought about by BAL. In other words the effect of BAL on urinary lead was greater in those cases in which there was already a high

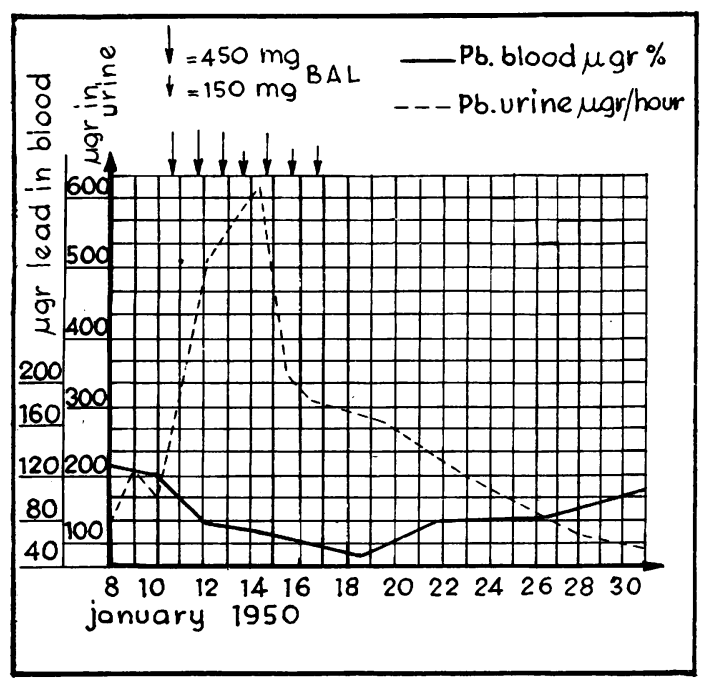

FIG. 2.-Effect of treatment with BAL on blood and urine.

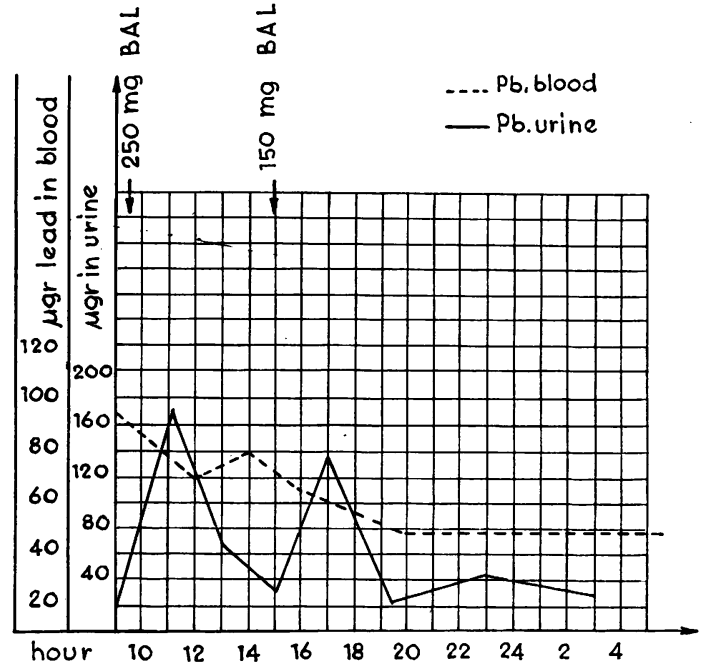

Fig. 3.-Effect of two injections of BAL on blood and urine lead level.

urinary lead excretion in relation to the quantity of lead in the blood (Table 1).

Taking the total mass of blood to be about $8 \%$ of the weight of the body the quantity of lead which disappeared from the blood three hours after an injection of BAL of 2 to $3 \mathrm{mg}$. per $\mathrm{kg}$. can be readily calculated. In our cases this quantity was on the average $2.1 \mathrm{mg}$. (maximum $3.4 \mathrm{mg}$., minimum 1.2 $\mathrm{mg}$.), whilst the quantity of lead eliminated in the urine in the same period was on the average 0.4 mg. ; maximum $0.8 \mathrm{mg}$., minimum $0.1 \mathrm{mg}$. (Table 2).

It thus is apparent that only a small part (about $1 / 5$ ) of the lead which leaves the blood after giving BAL passes over into the urine, the greater part is carried over into the tissues, probably mainly into the skeleton (Ginsburg and Weatherall, 1948). Three or four hours after the cessation of the action of BAL the lead which had passed into the tissues returns to the blood, bringing about the observed increase of blood lead which can be seen between the fourth and the eighth hour after the injection. This effect is seen to be greater in those cases in which the urinary excretion of lead was high in relation to the blood lead concentration and in which the elimination of lead had been found to be high in the urine as a result of BAL. If in a patient who had received an injection of BAL of 2 to $4 \mathrm{mg}$. per $\mathrm{kg}$., then a second injection of BAL is given more than three hours later or one or more days later, the same variations in blood and urine lead are seen as were produced by the first injection (Fig. 3). But if the injections are continued their effect becomes progressively less. 
TABLE 1

INCREASE IN EXCRETION OF URINARY LEAD AFTER INJECTION WITH BAL

\begin{tabular}{|c|c|c|c|c|c|c|c|}
\hline \multirow[b]{2}{*}{$\begin{array}{l}\text { Case } \\
\text { No. }\end{array}$} & \multirow[b]{2}{*}{ Name } & \multicolumn{2}{|c|}{ Before Injection of BAL } & \multirow[b]{2}{*}{$\begin{array}{c}\text { Ratio } \\
2 / 1\end{array}$} & \multirow{2}{*}{$\begin{array}{l}\text { BAL } \\
\text { Injected } \\
\text { (mg.) }\end{array}$} & \multicolumn{2}{|c|}{ After Injection of BAL } \\
\hline & & $\begin{array}{c}(\mu \text { g. Pb per } 100 \\
\text { ml. blood) } \\
1\end{array}$ & $\begin{array}{c}\text { (ug. } \mathrm{Pb} \text { in } 24- \\
\text { hour urine) } \\
2\end{array}$ & & & $\begin{array}{l}\text { (ug. } \mathrm{Pb} \text { in } 24- \\
\text { hour urine) } \\
3\end{array}$ & $\begin{array}{c}\text { Ratio } \\
3 / 2\end{array}$ \\
\hline 1 & P. Ang. & 260 & 216 & $0 \cdot 8$ & 200 & 431 & $2 \cdot 0$ \\
\hline 2 & T. Mar. & 134 & 150 & $1 \cdot 1$ & 200 & 408 & $2 \cdot 7$ \\
\hline 3 & R. Nat. & 122 & 160 & $1 \cdot 3$ & $2 \times 150$ & 326 & $2 \cdot 0$ \\
\hline 4 & B. Pie. & 88 & 124 & $1 \cdot 4$ & 100 & 303 & $2 \cdot 4$ \\
\hline 5 & M. Lue. & 165 & 309 & $1 \cdot 8$ & $3 \times 100$ & 440 & $1 \cdot 4$ \\
\hline 6 & C. Ado. & 138 & 280 & $2 \cdot 0$ & 150 & 584 & $2 \cdot 1$ \\
\hline 7 & D. Pao. & 110 & 225 & $2 \cdot 0$ & 150 & 650 & $2 \cdot 9$ \\
\hline 8 & B. Car. & 136 & 280 & $2 \cdot 0$ & 50 & 440 & $1 \cdot 6$ \\
\hline 9 & B. Mar. & 107 & 247 & $2 \cdot 2$ & $2 \times 120$ & 1129 & $4 \cdot 6$ \\
\hline 10 & D. Dad. & 36 & 98 & $2 \cdot 7$ & 150 & 216 & $2 \cdot 2$ \\
\hline 11 & V. Con. & 130 & 482 & $3 \cdot 7$ & 200 & 2376 & $4 \cdot 9$ \\
\hline 12 & R. Mar. & 98 & 400 & $4 \cdot 1$ & 400 & 1150 & $2 \cdot 9$ \\
\hline 13 & G. Pao. & 120 & 588 & $4 \cdot 9$ & 300 & 3167 & $5 \cdot 4$ \\
\hline
\end{tabular}

TABLE 2

TOTAL AMOUNT OF LEAD LOST FROM THE BLOOD AND THE URINARY LEAD OUTPUT AFTER BAL INJECTION

\begin{tabular}{|c|c|c|c|c|c|c|c|c|}
\hline \multirow[b]{2}{*}{$\begin{array}{l}\text { Case } \\
\text { No. }\end{array}$} & \multirow[b]{2}{*}{ Name } & \multirow[b]{2}{*}{$\begin{array}{l}\text { Weight } \\
\text { (kg.) }\end{array}$} & \multicolumn{3}{|c|}{ Pb per 100 ml. Blood ( $\mu$ g.) } & \multirow{2}{*}{$\begin{array}{l}\mathrm{Pb}(\mu \mathrm{g} .) \text { Lost from } \\
\text { Total Amount } \\
\text { of Blood } \\
(8 \% \text { body weight })\end{array}$} & \multirow{2}{*}{$\begin{array}{c}\text { Pb Eliminated in } \\
\text { Urine in First } 3 \\
\text { Hours after BAL } \\
(\mu \mathrm{g} .)\end{array}$} & \multirow{2}{*}{$\begin{array}{l}\text { Urinary } \mathrm{Pb} \text { as } \\
\text { Percentage of } \mathrm{Pb} \\
\text { Lost from } \\
\text { Total Blood }\end{array}$} \\
\hline & & & $\begin{array}{c}\text { Before } \\
\text { BAL }\end{array}$ & $\begin{array}{l}3 \text { Hours } \\
\text { after } \\
\text { BAL }\end{array}$ & $\begin{array}{c}\text { Absolute } \\
\text { Fall }\end{array}$ & & & \\
\hline 1 & C. Ado. & 63 & 138 & 71 & 67 & 3377 & 264 & $7 \cdot 8$ \\
\hline 2 & B. Pie. & 61 & 88 & 48 & 40 & 1952 & 99 & $5 \cdot 1$ \\
\hline 3 & B. Mar. & 53 & 108 & 69 & 39 & 1654 & 137 & $8 \cdot 2$ \\
\hline 4 & R. Mar. & 57 & 98 & 70 & 28 & 1277 & 525 & $41 \cdot 1$ \\
\hline 5 & G. Pao. & 64 & 120 & 62 & 58 & 2969 & 810 & $27 \cdot 3$ \\
\hline 6 & B. Enr. & 60 & 100 & 75 & 25 & 1200 & 386 & $32 \cdot 2$ \\
\hline
\end{tabular}

A series of one to three injections of BAL daily for several days in doses of 50 to $450 \mathrm{mg}$. a day brought about an increase in urinary lead for the first three to five days, followed by a reduction to the pre-treatment levels. Parallel with this effect the blood level fell to 30 or $40 \%$ of the original level. Cessation of the administration of BAL produced a tendency in the blood and urinary lead to return in a few days to approximately initial levels (Fig. 2).

A second course of injections brought about a new rise in the elimination of lead in the urine, and a fall in blood concentrations ; the effect, however, was much less marked than that brought about by the first series. Doses of 250 to $450 \mathrm{mg}$. BAL a day had a greater and more prolonged effect than small doses of 50 to $150 \mathrm{mg}$. per day. In the latter 


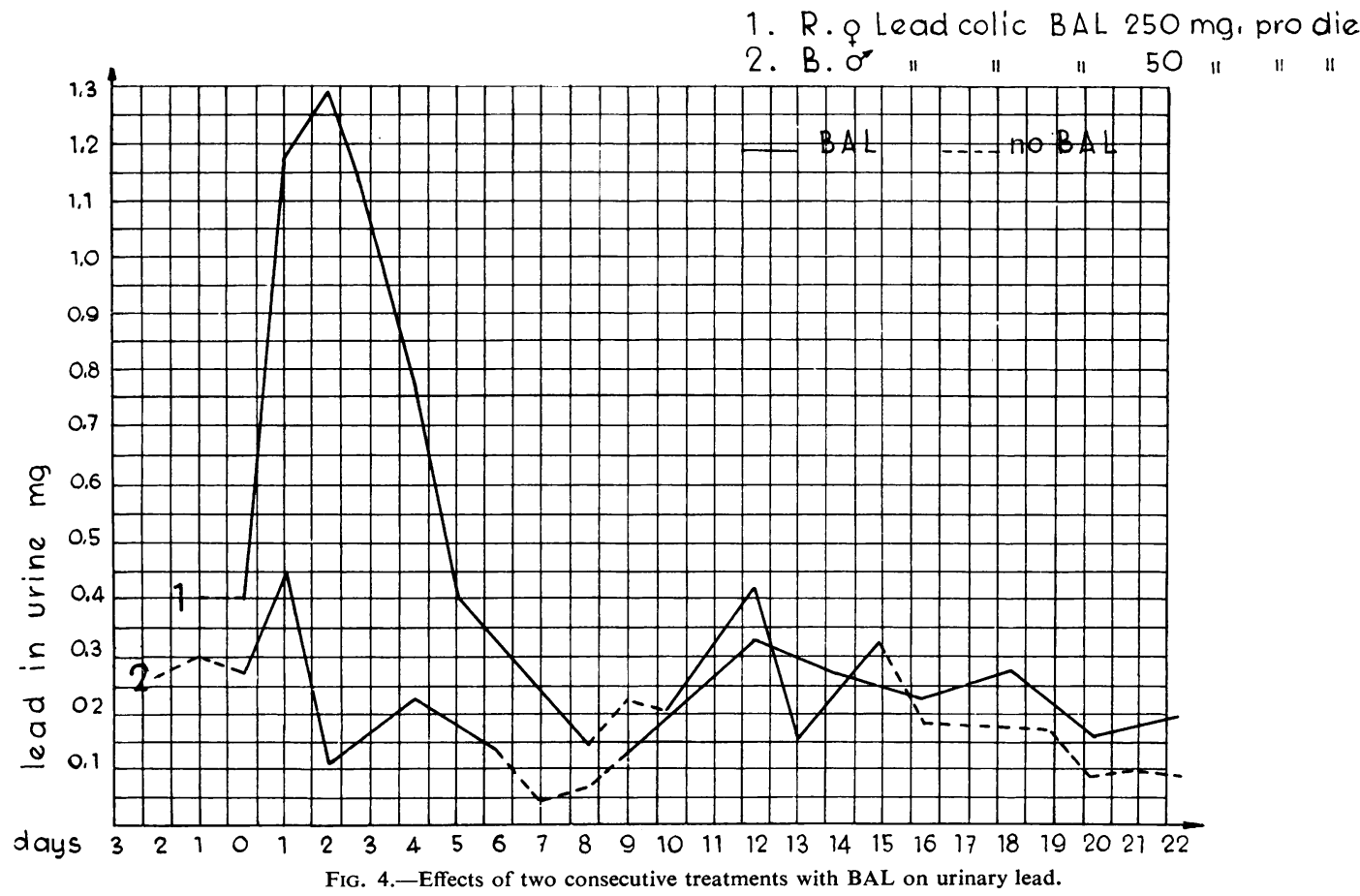

cases the rise in urinary lead lasted only two or three days, even when the BAL administration was continued for a considerable period (Fig. 4).

Lead in Bile and Gastric Juice.-Lead was determined in the bile and gastric juice in order to discover whether BAL caused a rise in lead excreted by the liver and stomach mucosa as had been found for the kidneys. This seemed probable inasmuch as it has been known for a considerable time that lead is secreted into the bile and gastric juice.

The test was carried out by introducing a gastric tube into the stomach or duodenum according to the fluid to be collected. After 30 minutes' control period BAL was injected in doses of 2 to $3 \mathrm{mg}$. per $\mathrm{kg}$., the bile and gastric juice being collected for one to three hours. The lead determination was carried out on the bile, collected every 30 minutes, and on the gastric juice aspirated every 15 minutes.

Lead in Bile.-No significant changes were observed in the quantity of lead excreted in the bile of three patients who were recovering from lead colic following the injection of $2 \mathrm{mg}$. per $\mathrm{kg}$. of BAL. In the hour following the injection the bile contained an increased concentration of lead, but as the volume issuing from the tube was small, the total excretion of bile remained almost unchanged. In the second hour there was neither change in lead concentration in the bile nor in the total quantity obtained. It must be concluded that, in contradistinction to what was found in the urine, BAL exercised little influence on the elimination of lead in the bile, at least during the first two hours after its administration.

Lead in Gastric Juice.-The elimination of lead in the gastric juice was studied in all cases after stimulation with an injection of histamine. Control observations were made in two patients convalescing from lead colic using histamine alone and without injections of BAL. In one of these a slight rise in the elimination of lead was observed between the first and second hours after the tube had been introduced into the stomach; in the other case the reverse phenomenon occurred. On the other hand, in three patients convalescing from lead colic in whom BAL had been injected during the removal of gastric juice, there was found a fall in the quantity of lead eliminated in this fluid running roughly parallel with the fall in the blood lead concentration.

Clinical Effects.-BAL treatment (4 to $14 \mathrm{mg}$. per $\mathrm{kg}$. per day) carried out in the course of lead colic sometimes caused an aggravation of symptoms. In one patient the effect of two injections of $2 \mathrm{mg}$. per $\mathrm{kg}$. separated by a period of seven hours was dramatic. After the second injection and whilst 


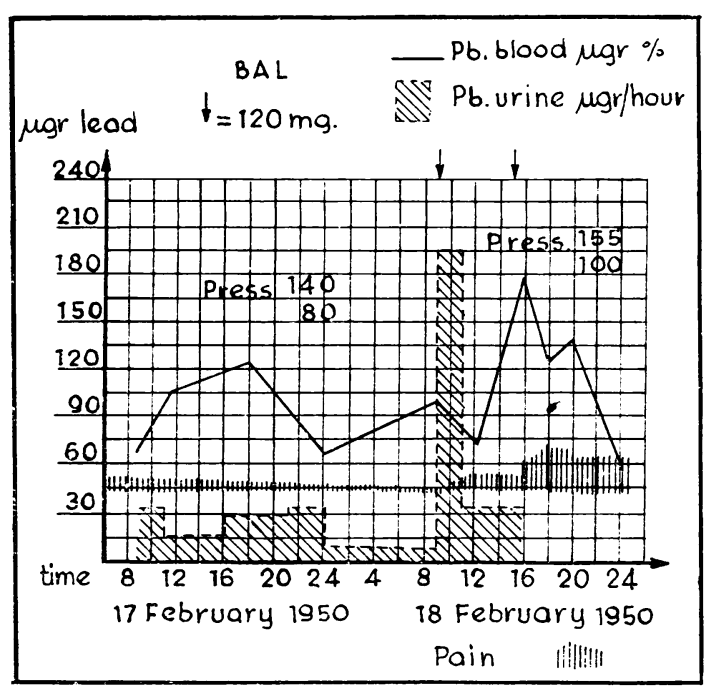

FIG. 5.-Chart of attack of lead encephalopathy following two injections of BAL.

the blood lead concentration was rapidly falling, there arose violent abdominal pain, hypertension, anuria for 16 hours, and an attack of acute encephalopathy (confusion state and severe psychomotor disturbance) lasting two to three days (Fig. 5). In other cases the treatment was tolerated without any adverse effect.

Treatment with BAL in the same dosage when the colic had already disappeared for some days brought about in a few cases a recurrence of abdominal pain, hypertension, and oliguria. Reduction of the dose of BAL to $3 \mathrm{mg}$. per $\mathrm{kg}$. or less per day prevented such recurrences. Such treatment in cases of lead intoxication in which the lead colic had disappeared for more than two weeks did not provoke any reappearance of symptoms. In some patients there was a strong impression of an improvement of the general condition, and especially of the appetite, body weight, and anaemia, in contrast to the picture presented by untreated patients.

The amount of urinary coproporphyrin during BAL treatment roughly followed the urinary lead. Thus a series of BAL injections brought about a marked reduction in urinary porphyrin after an initial rise.

\section{Discussion}

The numerous determinations of lead in blood and urine which have been carried out in our cases of lead poisoning and the marked changes in the distribution of lead in the organism which have been brought about by injections of BAL and which sometimes were followed by aggravation of symp- toms, seem to justify certain views on the aetiology and pathogenesis of some of the symptoms of lead poisoning.

There is no doubt that BAL exercises a rapid and intense action on the metabolism of lead. Our observations indicate that BAL combines rapidly with part of the lead contained in the red cells, forming a compound which can be stored in certain tissues and which is only in part eliminated via the kidneys, not at all, or only insignificantly, with the bile, and only slightly in the gastric juice. It is probable that this compound is not excreted at all through the digestive tract; indeed, Eagle (1948) could not detect any increase of lead in faeces after injection of BAL. After the cessation of BAL action lead returns from the tissues to the blood, thus re-establishing a situation almost identical with that prior to the injection.

With a series of injections of BAL for several days the displacement of lead from the blood into the tissues occurs more intensely and lasts longer, because there is no opportunity to return to preinjection levels between one injection and the next. In some sense, therefore, BAL produces a cumulative effect. Harmful effects attributable to BAL are usually encountered after several days of administration of quantities greater than $300 \mathrm{mg}$. per day, but only exceptionally after one or two injections. It has been maintained that only lead circulating in the blood is harmful (Schmidt and Weyrauch, 1933) whereas that deposited in the organs or in the tissues has no effect. This statement, however, is not borne out by the fact that the blood lead concentration bears no consistent relation to the appearance or severity of clinical signs and symptoms. It has therefore been suggested (Blumberg and Scott, 1935 ; Smith, Rathmell, and Marcil, 1938 ; Wexler and Sobel, 1935) that the clinical symptoms of lead poisoning are more directly related to the lead in the serum or plasma than to that in the whole blood. Our experiments and those of Lauer (1948) have shown that following the injection of BAL no change is found in plasma or serum lead, even when the BAL is re-evoking or aggravating a case of lead colic.

In several of our cases it was observed most clearly that the symptoms of colic appeared, or were aggravated, after the injection of BAL at a time when the quantity of lead in the blood was in fact diminishing. This suggests that it is not lead in the circulating red cells, or that dissolved in the plasma, which is harmful, but rather the lead which has rapidly shifted from the blood to the tissues, or even from one tissue to another, and that it accumulates in a short time and to an excessive degree in some organ or tissue which is particularly sensitive to its 
toxicological action. In our case of acute encephalopathy brought about by BAL, about $8 \mathrm{mg}$. of lead were transferred in four hours from the blood to the tissues, whilst additional lead migrated from one tissue to another (Ginsburg and Weatherall, 1948). It is possible that this notable transfer of lead may have caused its accumulation in the central nervous system, hence the appearance of encephalopathy. Indeed the largest oscillations of blood lead concentrations obtained by us following the injection of BAL were observed in this patient. The aggravation or the re-appearance of colic appears to be due to the migration of lead caused by BAL into elements of the nervous system, the stimulation of which provokes intestinal spasm and the other manifestations of colic. It may be that the intestine is not the tissue involved, for Eagle (1948) did not see any increase in the elimination of faecal lead after the injection of BAL, and we were not able to show any increase of secretion of lead across the gastric mucosa. Our observations tend to support the hypothesis that colic is caused by the alterations in the autonomic system.

Failure to demonstrate the excretion of lead in the bile after injections of BAL is a natural consequence of the transference of lead from the liver to other tissues as observed by Ginsburg and Weatherall (1948) ; similarly the fall in urinary coproporphyrin can be related to the diminution of lead in the bone marrow, also observed by Ginsburg and Weatherall (1948), and to the general view that coproporphyrins are formed as a result of a modification in the process of haemoglobin synthesis.

There has been much discussion on the usefulness of the process of de-leading. According to Aub, Fairhall, Minot, and Reznikoff (1926) de-leading means the mobilization of lead from the bones with an increase in its elimination. Kehoe and Thamann (1929) advise against any method resulting in rapid liberation of lead from the tissue deposits because such rapid elimination may be followed by the deposition of lead in the central nervous system. The danger of BAL treatment in lead poisoning has been attributed, indeed, to its powerful de-leading effect.

The principal effect of BAL does not consist in a de-leading effect, as ordinarily defined, but in a translocation of lead from the blood and certain organs to other organs. This is borne out by the observed fact that the effect of BAL is to bring about the fall of lead in the blood rather than an increase; the latter could logically have been expected if BAL simply mobilized the lead from the deposits in bone.

Further, the investigations of Ginsburg and Weatherall (1948) have shown that the effect of
BAL is to bring about a transference of lead from the liver, the blood, and the spleen to the skeleton.

Having regard to the great changes in the distribution of lead in the organism brought about by BAL, its effect upon the elimination of lead is relatively small. As a result of this shift in the lead, it accumulates in other organs, including the nervous system, in which it may, or could, produce damaging effects. The favourable effect of inducing a large elimination of urinary lead is thereby overcome by the unfavourable effect of an excessive translocation of lead within the organism.

If it were possible to find a remedy which would bring about only de-leading without any excessive shift in the tissue distribution of lead, it would probably constitute the best possible treatment of lead poisoning.

The final impression is that treatment with BAL is dangerous, and especially so in patients suffering from colic or other manifestations of acute lead poisoning ; in such cases the medicament should be used with great precaution and in small doses.

Further, we are of opinion that treatment with BAL continued for several consecutive days with two or more injections per day is less effective in eliminating lead and perhaps more dangerous than intermittent treatment, consisting of short cycles of one or two days separated one from the other by two or three days without BAL. The rationale of this scheme of treatment is not to lower the content of lead in the blood, but rather to eliminate as much lead as possible in the urine without at the same time too greatly altering the distribution of lead in the blood and in the tissues.

The fact that in certain cases BAL has caused toxic effects does not mean that it should be completely abandoned as a treatment for lead poisoning ; a final judgment is not yet possible until trials are carried out using BAL in small doses and for short periods in chronic lead intoxication.

\section{Summary}

Twenty-seven patients suffering from industrial lead intoxication were treated with injections of BAL. Fourteen of these were in a state of colic on their admission to hospital; the others had overcome the colic a few days or a few weeks earlier. The metabolism of lead was studied after a single injection of BAL in doses of 1 to $4 \mathrm{mg}$. per $\mathrm{kg}$., and in the course of treatment lasting for several days with daily doses of 1 to $7 \mathrm{mg}$. per $\mathrm{kg}$.

Following the injection of BAL a rapid fall in the blood lead level occurred which reached minimal values eight to 10 hours after the injection, and there was a great increase in urinary lead which reached its maximum one to two hours after the 
injection. Where a series of injections was given the blood lead level fell and urinary lead increased for the first few days ; but in the following days the effect of BAL became progressively less. After cessation of the administration of BAL the blood and urinary lead both tended to return to the initial values. A single injection of BAL has no evident effect on lead in the bile, but appears to bring about a diminution of lead eliminated in the gastric juice.

BAL has shown itself to be a rather dangerous medicament in lead poisoning; its administration during lead colic may aggravate the abdominal symptoms and make them re-appear, even after they had disappeared for several days. In one case of colic two injections of BAL separated by a seven-hour interval brought about an attack of acute encephalopathy. If, after the cessation of symptoms of colic for a week, BAL is administered in doses not greater than $4 \mathrm{mg}$. per $\mathrm{kg}$. per day, it is usually well tolerated and may perhaps accelerate the process of cure.

The principal pharmacological effect of BAL consists in a transposition of lead within the organism, from the blood and certain tissues towards other tissues, among which the nervous tissue must be considered. The value of the deleading effect of BAL is relatively small when the unfavourable effects due to disturbance in the internal distribution of lead are considered.

\section{REFERFNCES}

Angeleri, C. (1949). Med.d. Lavoro, 40, 265.

Aub, J. C., Fairhall, L. T., Minot, A. S., and Reznikoff, P. Lead Poisoning. In Medicine, 4, 1 (1926). Cited in Cantarow and Trumper. Williams and Wilkins, Baltimore, 1944

Blumberg, H., and Scott, T. F. McNair (1935). Bull. Johns Hopk. Hosp., 56, 32, 276, 311.

Eagle, H. (1948). Proc. Lead Hygiene Conference, Chicago, pp. 81-92. Ginsburg, M., and Weatherall, M. (1948). Brit. J. Pharmacol., 3,223 .

Kehoe, R. A., and Thamann, F. (1929). J. Amer. med. Ass., 92, 1418.

Lauer, D. J. (1948). Proc. Lead Hygiene Conference. Chicago, p. 98. Ryder, H, W.,Choiak, J., and Kehoe, R A (1947). Science, 106, 63. Schmidt, P., and Weyrauch, F. (1933). "Die Bleivergiftung im Schmidt, P., and Weyrauch, F. (1933). "

Smith, F. L., Rathmell, T. K., and Marcil, G. E. (1938). Amer. J. clin. Path., 8, 471.

Vigliani, E.C., Zurlo, N., Angeleri, C., Meschia, G., and Sartorelli, E. (1951). Atti Convegno Int. Med. Lavoro, Milano, 1950. Capella, Cirié, 1951.

Wexler, I. B., and Sobel, A. E. (1935). Proc. Soc. exp. Biol., N.Y. 